\title{
New highlights of phytolith structure and occluded carbon location: 3-D X-ray microscopy and NanoSIMS results
}

\author{
A. Alexandre ${ }^{1}$, I. Basile-Doelsch ${ }^{1}$, T. Delhaye ${ }^{2}$, D. Borshneck ${ }^{1}$, J. C. Mazur ${ }^{1}$, P. Reyerson ${ }^{3}$, and G. M. Santos ${ }^{4}$ \\ ${ }^{1}$ Centre Européen de Recherche et d'Enseignement des Géosciences de l'Environnement (UMR 7330), CNRS, Aix-Marseille \\ Université, Europôle méditerranéen de l’Arbois BP 80, 13545 Aix en Provence CEDEX 04, France \\ ${ }^{2}$ Plateforme NanoSIMS, OSUR, Université de Rennes 1, Campus de Beaulieu, 35042 Rennes CEDEX, France \\ ${ }^{3}$ Department of Geography, University of Wisconsin-Madison, 550 North Park Street, Madison, WI 53706, USA \\ ${ }^{4}$ Department of Earth System Science, University of California, Irvine, B321 Croul Hall, Irvine, CA 92697-3100, USA
}

Correspondence to: A. Alexandre (alexandre@cerege.fr)

Received: 29 August 2014 - Published in Biogeosciences Discuss.: 14 October 2014

Revised: 19 December 2014 - Accepted: 12 January 2015 - Published: 12 February 2015

\begin{abstract}
Phytoliths contain occluded organic compounds called phytC. Recently, phytC content, nature, origin, paleoenvironmental meaning and impact in the global $\mathrm{C}$ cycle have been the subject of increasing debate. Inconsistencies were fed by the scarcity of in situ characterizations of phytC in phytoliths. Here we reconstructed at high spatial resolution the 3-D structure of harvested grass short cell (GSC) phytoliths using 3-D X-ray microscopy. While this technique has been widely used for 3-D reconstruction of biological systems it has never been applied in high-resolution mode to silica particles. Simultaneously, we investigated the location of phytC using nanoscale secondary ion mass spectrometry (NanoSIMS). Our data evidenced that the silica structure contains micrometric internal cavities. These internal cavities were sometimes observed isolated from the outside. Their opening may be an original feature or may result from a beginning of dissolution of silica during the chemical extraction procedure, mimicking the progressive dissolution process that can happen in natural environments. The phytC that may originally occupy the cavities is thus susceptible to rapid oxidation. It was not detected by the NanoSIMS technique. However, another pool of phytC, continuously distributed in and protected by the silica structure, was observed. Its N / C ratio (0.27) is in agreement with the presence of amino acids. These findings constitute a basis to further characterize the origin, occlusion process, nature and accessibility of phytC, as a prerequisite for assessing its significance in the global $\mathrm{C}$ cycle.
\end{abstract}

\section{Introduction}

When absorbing nutrients in the soil, plants roots also uptake a significant amount of silicon $(\mathrm{Si})$. The $\mathrm{Si}$ fluxes recycled by plants are substantial; for example, Si take up by tropical forests or grasslands can reach 2 to 10 times Si fluxes generated from the dissolution of soil silicates that are exported to stream water (e.g., Blecker et al., 2006; Struyf and Conley, 2009; Cornelis et al., 2011; Alexandre et al., 2011). Inside the plant, $\mathrm{Si}$ is transported in the sap and deposited inside the cells, in the cell walls and in extracellular spaces of stems and leaves as micrometric hydrous amorphous silica particles called phytoliths. Upon plant decay, part of the phytolith production can be incorporated into soils or sediments and preserved for as long as millions of years (Alexandre et al., 2011; Miller et al., 2012; Strömberg et al., 2013). These fossil phytolith assemblages can be used for reconstructing past vegetation and climate conditions via their morphological and geochemical signatures (Piperno, 2006; Alexandre et al., 2012). Phytoliths occlude small amounts of organic compounds, first evidenced by the production of carbon $(\mathrm{C})$ and nitrogen $(\mathrm{N})$ during dry ashing (Jones and Beavers, 1963). Later on, scanning transmission electron microscopy (STEM) and energy dispersive X-ray (EDX) analyses of phytoliths in the plant tissues confirmed that the occluded organic compounds contained $\mathrm{C}, \mathrm{N}$ and phosphorus (P) (Laue et al., 2007). By extension, these occluded compounds are here called phytC. PhytC, which is assumed to be 
protected from natural oxidation by the siliceous structure, has been the subject of increasing attention and debate.

Based on the assumption that phytC originated from the photosynthesis of atmospheric $\mathrm{CO}_{2}$ in the host plant, several studies used phytC ${ }^{14} \mathrm{C}$ and $\delta^{13} \mathrm{C}$ signatures respectively as a dating tool (Piperno and Becker, 1996; Piperno and Stothert, 2003; McMichael et al., 2012) and a paleoenvironmental proxy (Kelly et al., 1991; Smith and White, 2004; Carter, 2009; Webb and Longstaffe, 2010; McInerney et al., 2011). However, very recently, ${ }^{14} \mathrm{C}$-AMS measurements of phytC samples from modern grasses yielded ages of several thousand years, which suggested that phytoliths may incorporate a substantial amount of old carbon, potentially from the soil (Santos et al., 2010, 2012). Amino acids from soils have been shown to be taken up by plants, and transported in small proportions to roots, stems and shoots (PaungfooLonhienne et al., 2008; Whiteside et al., 2009, 2012; Gao et al., 2010; Warren, 2012). Thus it is not inconsistent to assume that $\mathrm{C}$ and $\mathrm{N}$ derived from these soil amino acids have been trapped in phytoliths. Although the hypothesis still needs to be verified, it raises the question of the molecular nature of phytC. Several techniques such as high-performance liquid chromatography (HPLC), gas chromatography mass spectrometry (GC-MS), protein staining, micro-Raman analysis and X-ray photoelectron spectroscopy (XPS) have been used to characterize phytC and led to contradictory results, especially regarding the presence or not of amino acids (Harrison, 1996; Pironon et al., 2001; Smith and Anderson, 2001; Elbaum et al., 2009; Watling et al., 2011). The problem is that these methods were applied on phytolith concentrates that were not proven to be completely devoid of extraneous organic remains. Chemical extractions leading to high-purity phytolith concentrates are indeed difficult to implement. Although the absence of organic particles can be checked by scanning electron microscopy (SEM) coupled with EDX (Corbineau et al., 2013), the presence of extraneous organic remains on the phytolith surface cannot be accurately detected.

Differences in the efficiency of phytolith extraction protocols may also explain the inconsistencies in phytC quantification. Accurately quantifying the phytC is important for the assessment of its significance in the terrestrial $\mathrm{C}$ cycle. Multiple studies have recently claimed that phytC may play a role in atmospheric $\mathrm{CO}_{2}$ sequestration and climate change mitigation (Parr and Sullivan, 2005; Parr et al., 2010; Song et al., 2014; Huang et al., 2014; Li et al., 2014; Zuo et al., 2014), although the fluxes of phytC from vegetation to soils and the residence time of phytC in soils are still largely unknown. PhytC content as high as $20 \%$ dry weight was obtained when using a phytolith extraction method based on microwave digestion (Parr and Sullivan, 2014). This value was more than 20 to 200 times higher than the values obtained using a chemical method verified to be $100 \%$ efficient for removing extraneous organic particles (from 0.1 to $1 \%$ dry weight; Smith and White, 2004). The difference was somewhat justified by partial dissolution of phytC when using aggressive protocols. The assumption that phytC may be located at different sites in the silica structure, with different accessibility to oxidation, has been put forward (Parr and Sullivan, 2014). This assumption supplemented a previous one, widely found in the literature, that micrometric opaque areas observed by natural light (NL) microscopy on some phytoliths were holes containing the phytC (Prychid et al., 2003; Piperno, 2006; Carter et al., 2009; Song et al., 2012; Parr and Sullivan, 2014). No measurements were however performed to support any of these hypotheses.

Finally, the debates on content, location, nature, origin and paleoenvironmental meaning of phytC have been fed by the scarcity of in situ characterizations of phytC in phytoliths, despite few seminal works (Harrison, 1996; Laue et al., 2007). Here we reconstructed, at high spatial resolution, the 3-D structure of grass phytoliths using 3-D X-ray microscopy. Simultaneously, we characterized the location of phytC using nanoscale secondary ion mass spectrometry (NanoSIMS).

\section{Material and methods}

Grasses are among the main producers of phytoliths. The leaves of Triticum durum wheat (TD-F-L), were harvested in 2012 at the Genomics Research Centre in Fiorenzuola d'Arda (Italy). Hundreds of grams were made available to us for phytC investigation. Phytoliths were extracted from $50 \mathrm{~g}$ of dry leaves using a wet chemical protocol recently set up for geochemical analysis of phytC. The protocol was described in detail in Corbineau et al. (2013). The organic matter was oxidized with $\mathrm{H}_{2} \mathrm{SO}_{4}, \mathrm{H}_{2} \mathrm{O}_{2}, \mathrm{HNO}_{3}$ and $\mathrm{KClO}_{3}$, and potential remains on the phytolith surface were dissolved using $\mathrm{KOH}$ ( $\mathrm{pH}$ of 11). The absence of residual extraneous organic particles was checked using SEM-EDX (Corbineau et al., 2013). Dominant phytolith types were recognized according to Madella et al. (2005) using NL microscopy at $600 \times$ and $1000 \times$ magnifications. As expected, the grass short cell group (GSC) and the bulliform cell group dominated the assemblage. These groups, which form in all grass epidermis, also dominate phytolith assemblages produced by grasslands and recovered from soils (e.g., Alexandre et al., 2011). Several NL microscopy and SEM pictures, illustrating the composition of the TD-F-L phytolith assemblage were taken. For the purpose of morphological comparison, pictures of fossil GSC and bulliform phytoliths from available soil assemblages described in previous papers, were additionally taken.

The 3-D structure of the GSC phytoliths was reconstructed by X-ray imaging at the micro-scale, using a 3-D X-ray microscope Zeiss Ultra XRM L 200. A few phytoliths, randomly selected from the bulk sample, were deposited on the inner surface of a bevel-cut Kapton tube of $50 \mu \mathrm{m}$ internal diameter. Five individual GSC phytoliths were recognized by optical microscopy at $200 \times$ magnification and their position 
located for 3-D visualization. The principle of the 3-D X-ray microscopy technique is based on focusing the X-ray beam on a rotating sample using an optical lens; then transmitted $\mathrm{X}$-rays are diffracted by a Fresnel zone plate on a scintillator in front of an optical device to produce a $200 \times$ magnified image of the phytolith captured by a charge-coupled device $(\mathrm{CCD})$ image sensor. Using a $1 \mathrm{~K} \times 1 \mathrm{~K}$ detector, it leads to a voxel size of $63 \mathrm{~nm}$. The X-ray beam path is continuously flushed with helium to minimize the absorption of Xrays by air, the sample and the optics excepted. While this technique has been widely used for 3-D reconstruction of biological systems it has never been applied in high-resolution mode to silica particles. Analysis of the phytoliths proceeded at $150 \mathrm{~nm}$ resolution for a $65 \mu \mathrm{m}$ field of view, in conventional absorption contrast imaging mode at $8 \mathrm{keV}$ (copper rotating anode; power set at $40 \mathrm{kV}$ and $30 \mathrm{~mA}$ ). Using this mode, the contrast was generated both from the different $\mathrm{X}$ ray attenuation coefficients of the chemical elements composing the sample and from the density. A total of $901 \mathrm{X}$-ray projections were recorded between -90 and $+90^{\circ}$ at an angle step of $0.2^{\circ}$ and an exposure time of $80 \mathrm{~s}$ per view. After $20 \mathrm{~h}$ of analysis, reconstruction of the phytolith volume was performed using XMReconstructor (Zeiss Xradia software). The resulting stack of 2-D grayscale slices was then exported to Avizo Fire (FEI group) for further image processing.

NanoSIMS analyses were performed on cross sections of TD-F-L phytoliths embedded in epoxy resin. One milligram of phytoliths was deposited on polytetrafluoroethylene (PTFE) filters (9 mm i.d.) stuck onto double face tape. Polypropylene (PP) tubes (10 mm i.d. and $15 \mathrm{~mm}$ long) were placed on the tape, encircling the phytoliths. Epoxy resin (Araldite 100/Hardener 16) was slipped into the tubes up to $3 \mathrm{~mm}$ height and left to dry for $3 \mathrm{~h}$ at $40^{\circ} \mathrm{C}$. Resin of $7 \mathrm{~mm}$ height was added and left to dry for $48 \mathrm{~h}$ at $40^{\circ} \mathrm{C}$. Those two steps prevented the resin from leaking from the base of the tube. Embedded samples were taken off the tubes and polished with diamond paste up to $0.1 \mu \mathrm{m}$, until the PTFE filter was completely removed and cross sections of phytoliths were visible in NL microscopy. Samples were sawn into $4 \mathrm{~mm}$ thick blocks. Dozens of GSC phytoliths cross sections to be analyzed with the NanoSIMS were located by SEM. The NanoSIMS technique is based upon the sputtering of a few atomic layers from the surface of a sample induced by a primary ion bombardment. The primary ion impact triggers a cascade of atomic collision. Atoms and atomic clusters are ejected. During the ejection process, some atoms and clusters are spontaneously ionized. These secondary ions are characteristic of the composition of the analyzed area. They are separated according to their mass and an image of the intensity of the secondary ion beam is made for a selected mass (http:// www.cameca.com/instruments-for-research/sims.aspx. Over the past few years, the NanoSIMS technique has increasingly been used in geosciences to investigate the elemental and isotopic composition of organic and inorganic materials (Herrmann et al., 2007; Hatton et al., 2012; Mueller et al., 2012,
2013). The NanoSIMS technique however has only scarcely been used for measuring secondary ion emission from amorphous silica. One study showed NanoSIMS images of a thin section of a giant siliceous sponge spicule (several millimeters in diameter). A micrometric proteinaceous scaffold, which averaged $2 \% \mathrm{C}$ dry weight, could be detected in the siliceous structure (Müller et al., 2010). The NanoSIMS technique was also used for identifying silicification sites in rice roots (Moore et al., 2011). Here, we analyzed the intensities of $\left[{ }^{28} \mathrm{Si}\right]^{-},\left[{ }^{16} \mathrm{O}\right]^{-},\left[{ }^{24} \mathrm{C}_{2}\right]^{-}$and $\left[{ }^{26} \mathrm{CN}\right]^{-}$ions produced by selected areas of the GSC phytoliths polished cross sections using a Cameca NanoSIMS 50. The section was coated with $25 \mathrm{~nm}$ gold and introduced in the NanoSIMS. $\mathrm{A}[\mathrm{Cs}]^{+}$primary ion probe with $16 \mathrm{kV}$ primary ion impact energy and a $8 \mathrm{kV}$ secondary ion extraction voltage was used. The best adjustment for obtaining secondary ion images of $\left[{ }^{28} \mathrm{Si}\right]^{-},\left[{ }^{16} \mathrm{O}\right]^{-},\left[{ }^{12} \mathrm{C}\right]^{-}$and $\left[{ }^{26} \mathrm{CN}\right]^{-}$was the following: the selected phytolith surface were first pre-sputtered with a de-focused primary beam on a $60 \mu \mathrm{m} \times 60 \mu \mathrm{m}$ area for $3 \mathrm{~min}$. Then $256 \times 256$ pixel images were made using a $2.2 \mathrm{pA}$ primary ion current (primary diaphragm diameter of $300 \mu \mathrm{m}$ ) and a counting time of $10 \mathrm{~ms}$ per pixel for areas of $30 \mu \mathrm{m} \times 30 \mu \mathrm{m}$. Analyses with longer counting time or larger primary diaphragm/higher primary beam intensity were also tested. Secondary ion images of $\left[{ }^{28} \mathrm{Si}\right],\left[{ }^{16} \mathrm{O}\right]^{-}$, $\left[{ }^{12} \mathrm{C}\right]^{-}$and $\left[{ }^{26} \mathrm{CN}\right]^{-}$were processed using the Image J software (http://imagej.nih.gov/ij). Colors were assigned to different signal intensities, increasing from black to red. Images of the $\left[{ }^{26} \mathrm{CN}\right]^{-} /\left[{ }^{12} \mathrm{C}\right]^{-}$ratio were also created. Line scans were drawn across the analyzed surfaces and ion intensity vs. distance along the line were plotted.

For comparison with the NanoSIMS results, the $\mathrm{C}$ and $\mathrm{N}$ contents of the bulk TD-F-L phytolith sample were measured by chemiluminescence after combustion at $1350{ }^{\circ} \mathrm{C}$ (for $\mathrm{C}$ ) and $1000^{\circ} \mathrm{C}$ (for $\mathrm{N}$ ). The $\mathrm{C}$ and $\mathrm{N}$ contents of the epoxy resin were measured with an elemental analyzer (EA) after combustion at $1350{ }^{\circ} \mathrm{C}$.

\section{Results}

Three morphological categories of phytoliths, commonly found in grasses, constituted the bulk sample. SEM pictures of phytoliths placed on the aluminum mount illustrate these categories in Fig. 1. SEM pictures of cross sections of the same categories are shown in Fig. 2. For each category, the mode of silica deposition is specified below when it has been previously evidenced in SEM, TEM, fluorescence microscopy or NanoSIMS images of plant cross sections (Sangster and Parry, 1969; Sowers and Thurston, 1979; Harrison, 1996; Currie and Perry, 2007; Law and Exley, 2011; Moore et al., 2011). The first phytolith category is constituted by thin fragments of multi-cellular silica sheets, several tenths of a micrometer long and wide but less than a few micrometers thick (Figs. 1a, b, 2a, b). These silica "skeletons" (Sang- 


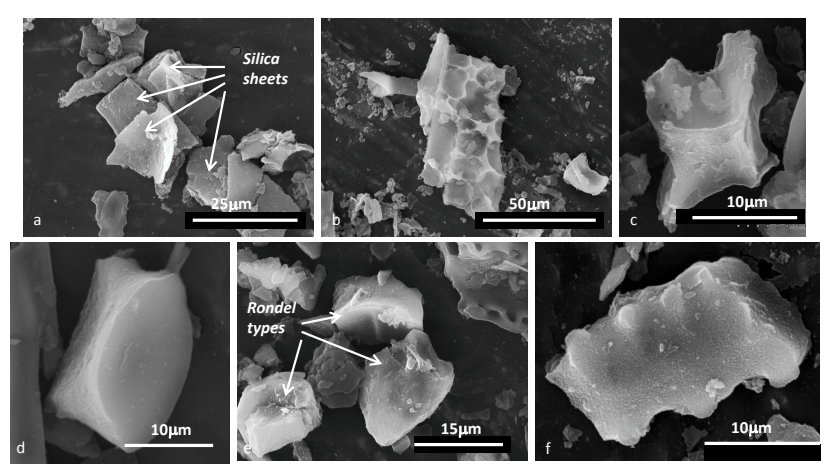

Figure 1. SEM images of TD-F-L wheat phytolith assemblage, deposited on an aluminum mount. Three categories are illustrated: (1) silica sheets (a, b), (2) stellate type from intercellular space (c) and (3) GSC phytoliths including rondel (d, e) and polylobate types (f).

ster and Parry, 1969; Law and Exley, 2011) were shown to result from the silicification of the middle lamella of the cells walls in grass epidermis and mesophyll, possibly as an early step of silicification (Laue et al., 2007; Law and Exley, 2012). Although abundant in plants (Piperno, 2006), the multi-cellular silica sheets are rapidly subjected to fragmentation and dissolution and are scarcely preserved in soils and sediments (Alexandre et al., 1994). The second phytolith category is constituted by stellate silica particles, of 10-15 $\mu \mathrm{m}$ width (Fig. 1c) that were shown to form in the intercellular spaces of the grass epidermis (Lins et al., 2002). This mode of silica precipitation was described as centripetal, starting as a narrow band lining the cavity, then partially or completely infilling the intercellular space (Sangster and Parry, 1981). The third category dominated the wheat phytolith assemblage. It is made of monocellular phytolith types of 10 $50 \mu \mathrm{m}$ of length, width and thickness. Most of them are GSC phytoliths and belong to the rondel (Fig. 1d, e) and polylobate (Fig. 1f) types. The formation of the monocellular phytolith type was also shown to be centripetal, starting in or against the cell walls and progressively infilling the lumen (e.g., Zhang et al., 2013). The processes that lead to complete silicification of the cells and to organic compounds occlusion are still unknown. Cellulose fibrils from the cell wall may regulate the silica formation (Laue et al., 2007).

SEM observations of cross sections of dozens of GSC phytoliths evidenced one or two internal cavities a few micrometers in diameter in the silica structure (Fig. 2c, d, e). They were similar in shape and size to the low electron density round area visible on one of the TEM image of phytoliths shown by Laue et al. (2007) (Fig. 2b of Laue et al., 2007). However, SEM observation of the GSC phytoliths just placed on the aluminum mount did not evidence any holes on the phytolith surface. When observed with NL microscopy (Fig. 3) the internal cavities were recognizable as opaque areas.
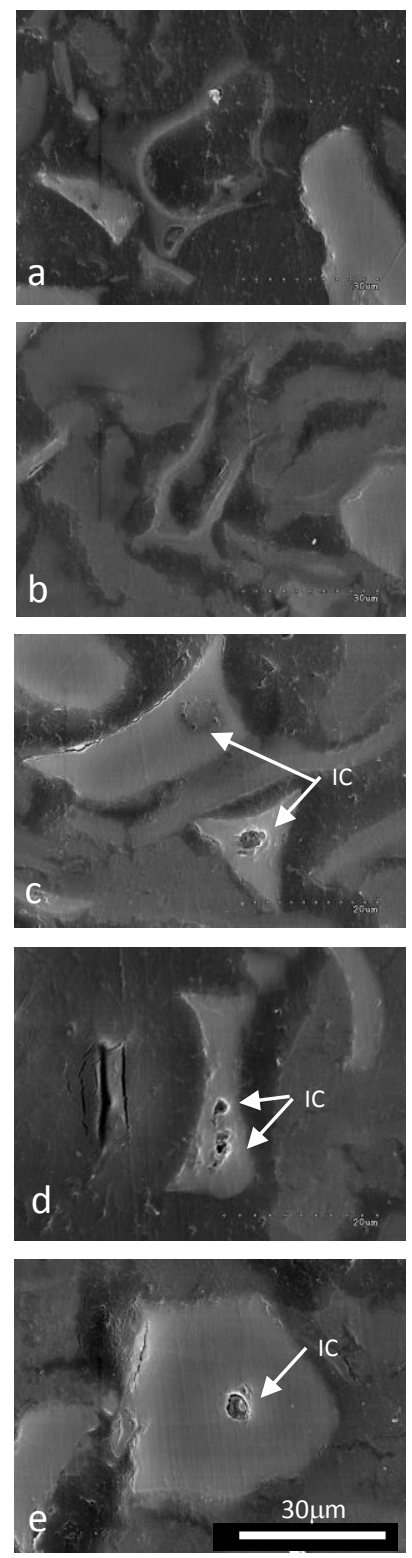

Figure 2. SEM images of the thin section of the TD-F-L wheat phytolith types including silica sheets $(\mathbf{a}, \mathbf{b})$, and GSC phytoliths of the rondel type (c, d, e). GSC types show micrometric internal cavities (IC). 


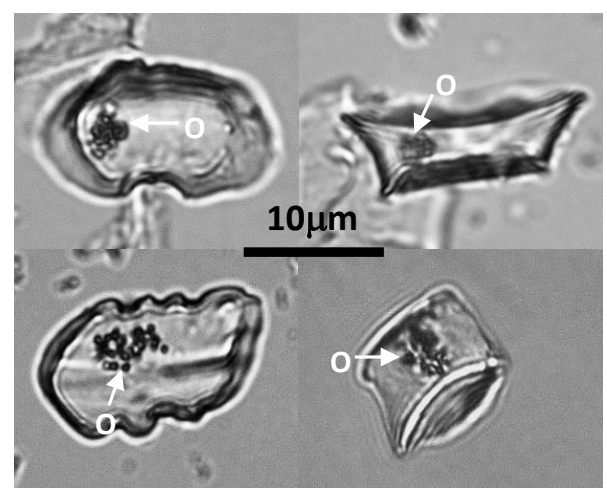

Figure 3. NL microscopy images of GSC phytolith types from the wheat TD-F-L sample showing opaque areas $(\mathrm{O})$.

Two examples of reconstructed 3-D X-ray microscopy volumes are presented in Figs. 4 and 5. The observed patterns were common to the five analyzed GSC particles. The siliceous structure appeared porous at the sub-micrometer scale (Figs. 4a and 5a). Inside the structure, areas of a few micrometers in diameter, with significantly lower X-ray absorption than the surrounding, were observed (Fig. 4a). 2-D planes of the reconstructed volumes evidenced that these heterogeneities were the cavities several micrometers wide previously identified on the cross sections by SEM. The cavities were interconnected (Figs. 4b, 5b). Some particles showed cavities isolated from the phytolith surface by a few micrometer thick silica wall (Fig. 4b). Other particles showed cavities connected to the phytolith surface by small holes of $0.1 \mu \mathrm{m}$ diameter only (Fig. 5b). These cavities appeared to be filled with air (no X-ray absorption), although the high contrast in X-ray absorbance between silica and air may have masked the presence of organic compounds.

The NanoSIMS results, common to the dozens of analyzed phytolith thin sections, are illustrated in Figs. 6-8. Adjustments were done to find the pre-sputtering duration ( $3 \mathrm{~min}$ ), the primary ion beam intensity $(\mathrm{L} 1=2 \mathrm{kV})$, the primary diaphragm diameter $(750 \mu \mathrm{m})$ and the duration of analyses (11 min) appropriate for obtaining sufficient total ion current (TIC) and avoid charging effects (Figs. 6a, 7a). When the primary ion beam intensity was increased to $\mathrm{L} 1=4 \mathrm{kV}$ (Fig. 8a), when the primary diaphragm diameter was decreased to $300 \mu \mathrm{m}$ (Fig. 8b), or when a succession of analyses resulted in increasing the duration of sputtering (Fig. 8c), a zone devoid of secondary ion signal appeared at the center of the silica surface. This was probably due to charging (Mueller et al., 2012) and/or to topographic heterogeneity (Winterholler et al., 2008). As silica was more resistant to polishing than the epoxy, silica surfaces were often convex (Fig. 8). The tests conducted here emphasized the importance of looking for the most efficient adjustment (i.e., avoiding charging and topographic effects) before performing NanoSIMS analyses on silica surfaces. $\left[{ }^{28} \mathrm{Si}\right]^{-},\left[{ }^{16} \mathrm{O}\right]^{-},\left[{ }^{12} \mathrm{C}\right]^{-}$and $\left[{ }^{26} \mathrm{CN}\right]^{-}$images clearly individualized phytoliths from the epoxy resin. The $\left[{ }^{28} \mathrm{Si}\right]^{-}$and $\left[{ }^{16} \mathrm{O}\right]^{-}$images and scan lines showed that phytoliths were made of a continuous silica structure (Figs. 6 and 7) sometimes interrupted by central micrometric areas devoid of silica (Fig. 7). This is again in concordance with the central cavities identified in SEM and 3-D X-ray imaging. Carbon was present in the cavities and in the silica structure itself. However when values of $\left[{ }^{12} \mathrm{C}\right]^{-}$intensity were similar in the cavities and in the epoxy resin, they were 10 to 20 times lower in the silica structure than in the epoxy resin (Figs. 6 and 7). $\mathrm{N}$ was also present in the silica structure and $\left[{ }^{26} \mathrm{CN}\right]^{-}$intensity was 3 to 4 times lower in the silica structure than in the cavities or the epoxy (Figs. 6 and 7). Interestingly, the $\left[{ }^{26} \mathrm{CN}\right]^{-} /\left[{ }^{12} \mathrm{C}\right]^{-}$ratio ranged between 20 and 30 in the silica structure and between 5 and 10 in the cavities and the epoxy. The silica structure was thus enriched in $\mathrm{N}$ by a factor of 4 to 8 relative to the surrounding epoxy. These features were reproducible from a particle to another. Bulk C and $\mathrm{N}$ contents in phytoliths, measured by chemiluminescence and EA (cf. Sect. 2), were 0.4 and $0.1 \%$ dry weight for phytoliths, and 68.8 and $2.8 \%$ dry weight for the epoxy resin, respectively. The $\mathrm{N} / \mathrm{C}$ ratio was 0.27 for the phytoliths and 0.04 for the epoxy resin. The bulk phytolith sample was thus enriched in $\mathrm{N}$ relative to the epoxy resin by a factor of 6.8, in agreement with $\mathrm{N}$ enrichments calculated from the NanoSIMS data. This consistency strengthened the accuracy of the $\left[{ }^{12} \mathrm{C}\right]^{-}$and $\left[{ }^{26} \mathrm{CN}\right]^{-}$relative intensities measured with the NanoSIMS. Finally, $\left[{ }^{26} \mathrm{CN}\right]^{-} /\left[{ }^{12} \mathrm{C}\right]^{-}$NanoSIMS images clearly showed that organic compounds, with $\mathrm{N}$ content significantly higher than in the resin, were continuously distributed (at the sub-micrometer scale) in the silica structure. On the contrary, cavities appeared to be filled with the epoxy resin.

\section{Discussion}

\subsection{PhytC locations in the silica structure of GSC phytoliths}

SEM, 3-D X-ray microscopy and NanoSIMS images showed that the silica structure of GSC phytoliths was homogeneous at the micrometric scale and systematically contained central micrometric interconnected cavities. The fact that some particles contained cavities isolated from the outside suggests that the opening to the outside can be either original or result from dissolution after the phytolith formation. Phytoliths often contain up to a few percent by dry weight of aluminium (Al) by dry weight (Bartoli and Wilding, 1980; Carnelli et al., 2004) co-precipitating with silica (Hodson and Sangster, 1993). As Al dissolves in strong acids and in strong bases, the phytolith chemical extraction procedure that included $\mathrm{HNO}_{3}$ and $\mathrm{H}_{2} \mathrm{SO}_{4}$ steps may have initiated phytolith surficial dissolution and opened the few micrometer thick sil- 


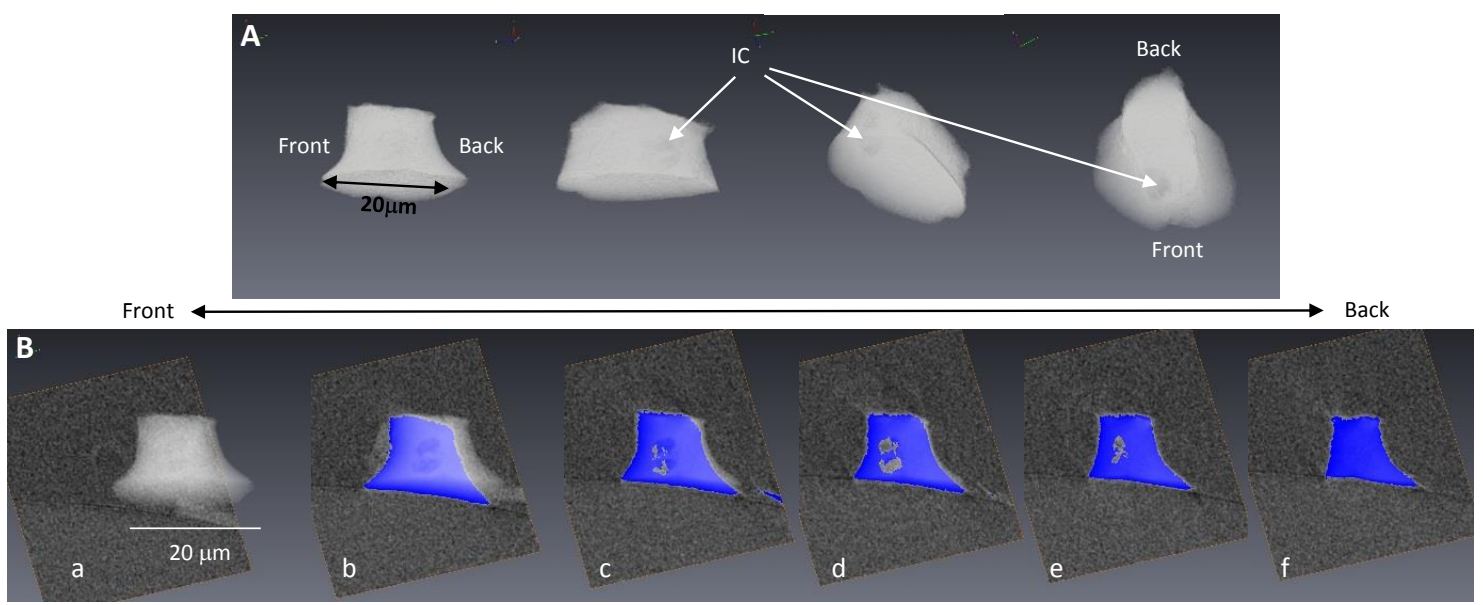

Figure 4. 3-D X-ray microscopy of a GSC phytolith from wheat (TD-F-L): (a) four views of the reconstructed volumes; internal cavities (IC) are distinguishable. (b) 2-D X-ray slices superimposed on the phytolith volume rendering, showing from front to back the internal cavity (IC). No connection to the surface was evidenced. The blue area corresponds to the thresholding of the phytolith grayscale values.

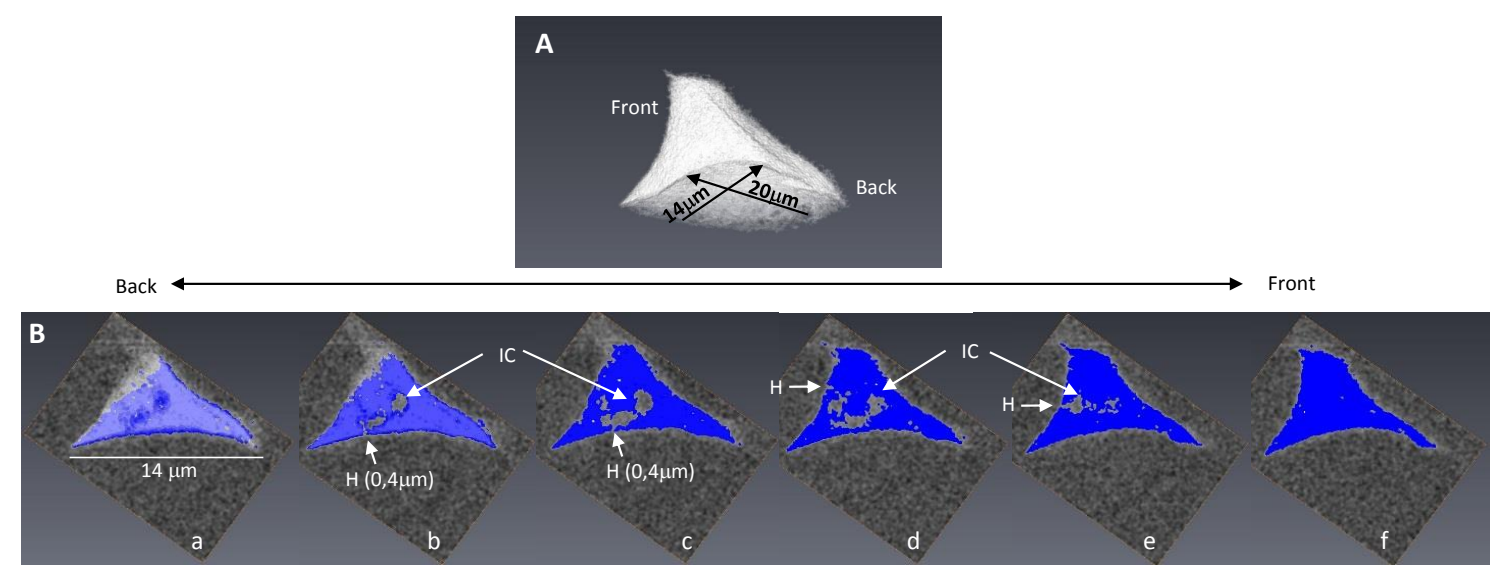

Figure 5. 3-D X-ray microscopy of a GSC phytolith from wheat (TD-F-L): (a) reconstructed volume. (b) 2-D X-ray images from back to front of the phytolith showing the internal cavity (IC) and its connection to the surface, forming holes (H). The blue area corresponds to the thresholding of the phytolith grayscale values.

ica wall between the cavities and the phytolith surface. The procedure also included a final alkaline step $(\mathrm{KOH}$ solution at $\mathrm{pH}$ 11) that may also have increased the dissolution features on the silica surfaces. As phytoliths were directly extracted from the plant, the surficial dissolution was revealed here at its beginning. It is expected to reach higher degrees over time in natural environments where multiple dissolution factors come into play (Iler, 1979). Large dissolution features were indeed often observed on fossil phytoliths and were quantified to assess the degree of weathering of soil phytolith assemblages (Alexandre et al., 1999; Oleschko et al., 2004). To illustrate this point, SEM and NL microscopy images of the entirety and cross sections of fossil monocellular phytoliths collected from soils are shown in Fig. 9. The phytolith types are characteristic of grass epidermis (GSC types and Cuneiform bulliform types; Madella et al., 2005)
(Fig. 9a, b) and wood parenchyma (globular granulate type; Madella et al., 2005) (Fig. 9c). The dissolution of silica has made central depressions of several micrometers wide. The particles appear empty inside, which is consistent with dissolution starting from the silica walls located between the cavities and the phytolith surface, then slightly opening, or increasing the opening of the cavities to the outside, and then enlarging the cavities into dissolution depressions. Such dissolution depressions are not limited to GSC phytoliths. They were observed on many types of monocellular phytoliths from grasses and non-grasses extracted from soils and sediments as illustrated in Fig. 9a5 (Acicular type), 9b2 and 9b3 (globular granulate). This implies that the inner part of all these phytolith types was constituted by silica less dense than the outer part, either due to phytC occlusion or to a lack of 


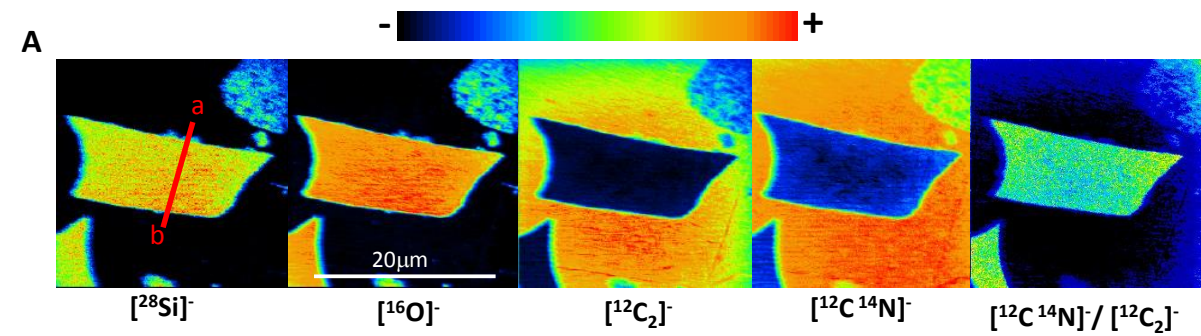

B
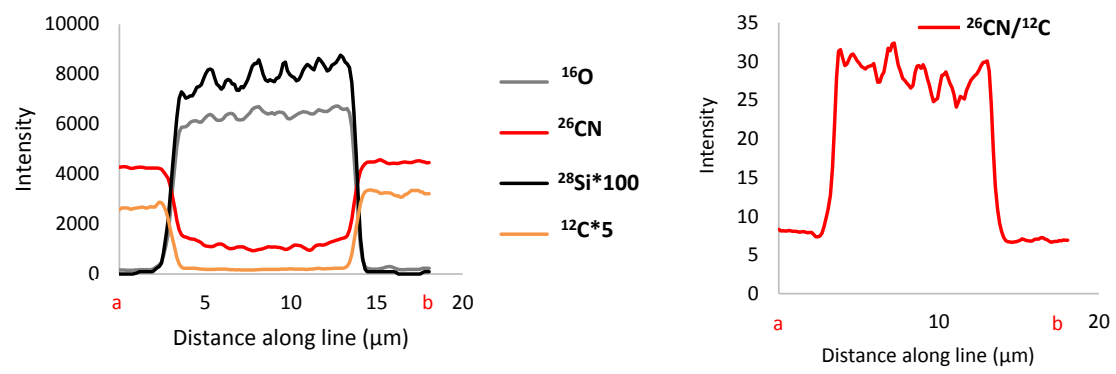

Figure 6. NanoSIMS images and intensities of a first typical GSC phytolith (rondel type) from TD-F-L (wheat) embedded in epoxy resin (polished section). Pre-sputtering: $\mathrm{L} 1=2 \mathrm{kV}$ de-focused $(60 \times 60 \mathrm{~mm})[\mathrm{Cs}]^{+}$primary beam, for $3 \mathrm{~min}(\mathbf{a})\left[{ }^{28} \mathrm{Si}\right]^{-},\left[{ }^{16} \mathrm{O}\right]^{-},\left[{ }^{12} \mathrm{C}_{2}\right]^{-},\left[{ }^{12} \mathrm{C}^{14} \mathrm{~N}\right]^{-}$ and $\left[{ }^{12} \mathrm{C}^{14} \mathrm{~N}\right]^{-} /\left[{ }^{12} \mathrm{C}_{2}\right]^{-}$images obtained with a $[\mathrm{Cs}]^{+}$primary beam with $\mathrm{L} 1=2 \mathrm{kV}$, D1-1 primary diaphragm $(750 \mu \mathrm{m})$, for $11 \mathrm{~min}$; $(\mathbf{b})$ secondary ion intensities along line scans (red line in a).

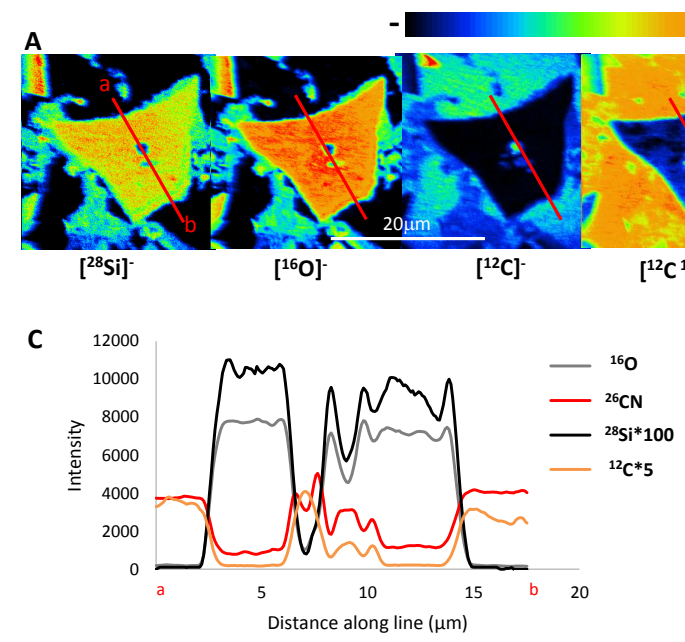

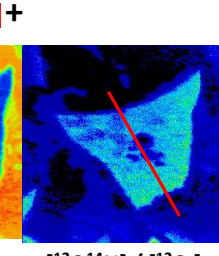

$\left[{ }^{12} \mathrm{C}^{14} \mathrm{~N}\right]^{-} \quad\left[{ }^{12} \mathrm{C}^{14} \mathrm{~N}\right] /\left[{ }^{12} \mathrm{C}_{2}\right]$

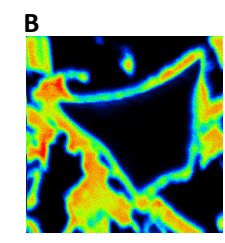

$\left.{ }^{28} \mathrm{Si}\right]^{-}$

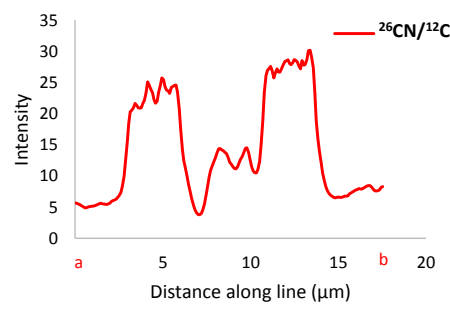

Figure 7. NanoSIMS images and intensities of a second typical GSC phytolith (rondel type) from TD-F-L (wheat) embedded in epoxy resin (polished section). Pre-sputtering: $\mathrm{L} 1=2 \mathrm{kV}$ de-focused $(60 \times 60 \mathrm{~mm})[\mathrm{Cs}]^{+}$primary beam, for $3 \mathrm{~min}(\mathbf{a})\left[{ }^{28} \mathrm{Si}\right]^{-},\left[{ }^{16} \mathrm{O}\right]^{-},\left[{ }^{12} \mathrm{C}_{2}\right]^{-}$, $\left[{ }^{12} \mathrm{C}^{14} \mathrm{~N}\right]^{-}$and $\left[{ }^{12} \mathrm{C}^{14} \mathrm{~N}\right]^{-} /\left[{ }^{12} \mathrm{C}_{2}\right]^{-}$images obtained with a $[\mathrm{Cs}]^{+}$primary beam with $\mathrm{L} 1=2 \mathrm{kV}, \mathrm{D} 1-1$ primary diaphragm $(750 \mu \mathrm{m})$, for $11 \mathrm{~min}$; (b) $\left.{ }^{28} \mathrm{Si}\right]^{-}$image obtained with a $[\mathrm{Cs}]^{+}$primary beam increased with $\mathrm{L} 1=4 \mathrm{kV}, \mathrm{D} 1-1$ primary diaphragm, for $11 \mathrm{~min}$; (c) secondary ion intensities along line scans (red line in Fig. 5a).

dissolved Si available for precipitation during the phytolith formation.

Inside the internal cavities, no original organic compounds could be detected by NanoSIMS. If initially present, they may have been squeezed out and replaced by the epoxy resin during the polishing step. On the contrary, the $\left[{ }^{26} \mathrm{CN}\right]^{-} /\left[{ }^{12} \mathrm{C}\right]^{-}$images clearly evidenced the presence of organic compounds rich in $\mathrm{N}$ continuously distributed in the silica structure and clearly differentiated from the epoxy resin. The absolute composition of $\left[{ }^{26} \mathrm{CN}\right]^{-}$and $\left[{ }^{12} \mathrm{C}\right]^{-}$was not calculated. This would have required including standard materials with known composition in the analyzed section. However, the consistency of $\mathrm{N}$ enrichment of the organic compound in the silica structure (measured by NanoSIMS) with $\mathrm{N}$ enrichment of the bulk phytC (measured by chemiluminescence/EA) supports the claim that the organic com- 


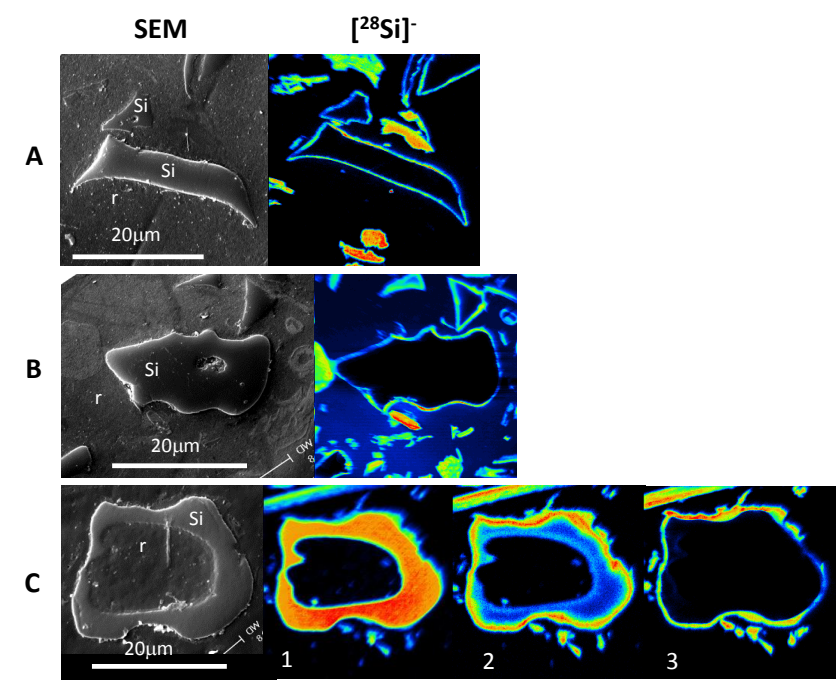

Figure 8. SEM images of the polished section showing convex silica surfaces $(\mathrm{Si})$ in the epoxy resin (r). Associated NanoSIMS $\left[{ }^{28} \mathrm{Si}\right]^{-}$images showing central areas devoid of secondary ion signal. (a) $[\mathrm{Cs}]^{+}$primary beam with $\mathrm{L} 1=4 \mathrm{kV}, \mathrm{D} 1-1$ primary diaphragm $(750 \mathrm{~mm}), 11 \mathrm{~min}$; (b) $[\mathrm{Cs}]^{+}$primary beam with $\mathrm{L} 1=2 \mathrm{kV}, \mathrm{D} 1-2$ primary diaphragm $(300 \mu \mathrm{m}), 11 \mathrm{~min}$; (c) $[\mathrm{Cs}]^{+}$ primary beam with $\mathrm{L} 1=2 \mathrm{kV}, \mathrm{D} 1-1$ primary diaphragm $(750 \mu \mathrm{m})$, 3 min analyses for 1,2 and 3 successively.

pound measured by NanoSIMS is phytC. Finally, although our data cannot be used to conclude the presence or absence of any phytC in the internal cavities, they demonstrate that the phytC is, in whole or in part, continuously distributed in the silica structure.

\subsection{Implications regarding phytC occlusion and phytC accessibility}

Evidence of the continuous distribution of phytC in the silica structure, at the sub-micrometric scale, suggests that it had been occluded since the early stage of silicification. SEM, environmental scanning electron microscope (ESEM) and TEM-EDX analyses showed that silica first precipitates in the inner cell wall, probably triggered by the presence of callose or lignin (Laue et al., 2007; Law and Exeley, 2011; Zhang et al., 2013). Silica nanospheres are then organized in a variety of structural motifs such as sheet-like, globular and fibrillar bundles that, from the cell wall, infill the cell lumen in a centripetal way (e.g., Kaufman et al., 1981; Sangster and Parry, 1981; Perry et al., 1987; Laue et al., 2007; Zhang et al., 2013), until most of the cell becomes silicified (Motomura, 2004; Laue et al., 2007). As previously noted, an organic template may participate to the silica formation Harrison, 1996; Laue et al., 2007). This organic template, progressively trapped in the silica structure, may constitute the phytC evidenced by NanoSIMS in the phytoliths. Its $\mathrm{N} / \mathrm{C}$ value (0.27) is in the range of $\mathrm{N} / \mathrm{C}$ values characteristic of amino acids. Amino acids may originate either from the cell itself or from

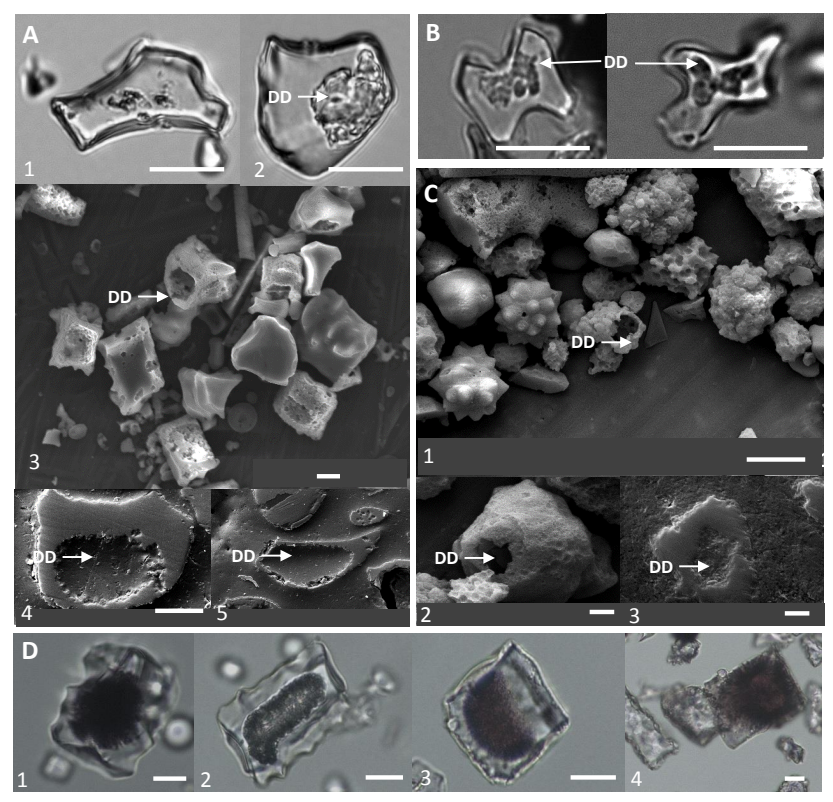

Figure 9. NL microscopy and SEM images of dissolution depressions (DD) affecting fossil phytoliths from soils. (a) Grass epidermis monocellular phytoliths (cuneiform bulliform types and acicular type) from Mascareignite (MSG 70, La Réunion, France) (Crespin et al., 2008); NL microscopy phytolith surface (1, 2), SEM phytolith volume (3) and polished section $(4,5)$. (b) Grass epidermis monocellular phytoliths from a ferrugineous soil (Salitre, Brazil) (Alexandre et al., 1999); NL microscopy phytolith. (c) Phytoliths from palms and trees from a ferallitic soil (Dimonika, RDA) (Alexandre et al., 1997); SEM globular granulate type volumes (1, 2) and polished section (3). (d) Opaque areas observed with NL microscopy on bulliform cell phytoliths from MSG $70(1,2)$ and Salitre $(3,4)$. Scale bars: $10 \mu \mathrm{m}$.

the extra-cellular space. Different families of transporters have been identified for their import into plant cells (Tegeder, 2012). At the same time, amino acids entering the cell simultaneously to silica thanks to an invagination/vesicle formation mechanism previously evidenced (Neumann and De Figueiredo, 2002) may occur.

At the end of the cell silicification, residual cell organic compounds that were not already occluded may gather in any remaining space and delimitate the micrometric central cavities. This second pool of phytC should be rapidly oxidized when phytoliths start to dissolve after their deposition in litter, soil or sediment (Fig. 9). This suggests that this phytC pool participates to a limited extent in long-term atmospheric $\mathrm{CO}_{2}$ sequestration. These considerations rise the need to further estimate the respective contributions to $\mathrm{C}$ contents measured from bulk phytolith concentrates of (i) phytC in the silica structure, (ii) phytC in the central cavities and (iii) extraneous $\mathrm{C}$ that may remain on porous phytolith surfaces. This is a prerequisite for reliable assessments of the significance of phytC in atmospheric $\mathrm{CO}_{2}$ sequestration. For that purpose, phytC contents measured from phytolith assem- 
blages characterized by 3-D X-ray microscopy as dominated by phytoliths with closed internal cavities or by phytoliths with open cavities should be compared.

\subsection{Reassessment of NL microscopy observations}

Several studies have speculated that opaque areas observed by NL microscopy in fossil phytoliths from soils and sediments were burnt organic remains indicative of past fire occurrence (Kealhofer and Penny, 1998; Elbaum et al., 2003; Parr, 2006; Piperno, 2006). However, when observed by NL microscopy, the empty dissolution depressions evidenced by SEM on monocellular phytoliths from soils (Fig. 9a) also appeared as opaque areas, especially when they were oriented downwards (Fig. 9c). This is probably due to trapped air in the dissolution depressions that caused an optical artifact at the place where the air met the mounting medium. This feature implies that opaque areas in fossil phytoliths should not be considered as unequivocal evidence of burnt organic compounds. Similarly, internal cavities may also appear as opaque spots due to the occurrence of trapped air, independent of the presence of organic compounds.

\section{Conclusions}

3-D X-ray microscopy reconstructions of GSC phytoliths from harvested grasses, and SEM observations of their cross sections, showed that the silica structure contains micrometric internal cavities. These cavities were sometimes observed isolated from the outside. Their opening may be an original feature or may result from the silica dissolution during the chemical extraction procedure, mimicking the beginning of dissolution process that may happen in natural environments. The phytC that may originally occupy those cavities is thus susceptible to rapid oxidation. It was not detected by the NanoSIMS technique. On the contrary, another pool of phytC, continuously distributed in and protected by the silica structure was evidenced by NanoSIMS. Its $\mathrm{N} / \mathrm{C}$ ratio $(0.27)$ is in agreement with the presence of amino acids. These findings constitute a basis to further characterize the origin, occlusion process, nature and accessibility of phytC, necessary for assessing its significance in the global $\mathrm{C}$ cycle.

Acknowledgements. The authors gratefully acknowledge support from LABEX OT-Med (France) (2013-2014 grant to A. Alexandre), from the U.S. National Science Foundation (DEB-1144888 to GMS) and from the "Investissements d'Avenir" French Government program of the French National Research Agency that funded the French X-ray CT platform Nano-ID (ANR-10-EQPX-39-01). NanoSIMS analyses were conducted at the Plateforme NanoSIMS, OSUR, Université de Rennes 1, France. We express special thanks to Franz Badeck and Luigi Cattivelli (CRA - Genomic Research Centre, Fiorenzuola d'Arda, Italy) for providing the wheat sample. The authors would like to thank two anonymous reviewers and Jack Middelburg, Biogeosciences associate editor, for their valu- able comments and suggestions for improving the manuscript.

Edited by: J. Middelburg

\section{References}

Alexandre, A., Colin F., and Meunier J.-D., Phytoliths as indicators of the biogeochemical turnover of silicon in equatorial forest, Compte-rendus de l'Académie des Sciences, Paris, 319, 453458, 1994.

Alexandre, A., Meunier, J. D., Colin, F., and Koud, J. M., Plant Impact on the Biogeochemical Cycle of Silicon and Related Weathering Processes, Geochim. Cosmochim. Ac., 61, 677-682, 1997.

Alexandre, A., Meunier, J. D., Mariotti, A., and Soubies, F.: Late Holocene phytolith and carbon isotope record from a latosol at Salitre, south-central Brazil, Quaternary Res., 51, 187-194, 1999.

Alexandre, A., Bouvet, M., and Abbadie, L.: The role of savannas in the terrestrial Si cycle: a case-study from Lamto, Ivory Coast, Global Planet. Change, 78, 162-169, 2011.

Alexandre, A., Crespin, J., Sylvestre, F., Sonzogni, C., and Hilbert, D. W.: The oxygen isotopic composition of phytolith assemblages from tropical rainforest soil tops (Queensland, Australia): validation of a new paleoenvironmental tool, Clim. Past, 8, 307324, doi:10.5194/cp-8-307-2012, 2012.

Bartoli, F. and L. P. Wilding. Dissolution of Biogenic Opal as a Function of Its Physical and Chemical Properties, Soil Sci. Soc. Am. J., 44, 873-878, 1980.

Blecker, S. W., McCulley, R. L., Chadwick, O. A., and Kelly, E. F.: Biologic cycling of silica across a grassland bioclimosequence, Global Biogeochem. Cy., 20, GB3023, doi:10.1029/2006gb002690, 2006.

Carnelli, A. L., Theurillat, J. P., and Madella, A.: Phytolith types and type-frequencies in subalpine-alpine plant species of the European Alps, Rev. Palaeobot. Palyno., 129, 39-65, 2004.

Carter, J. A.: Atmospheric carbon isotope signatures in phytolithoccluded carbon, Quatern. Int., 193, 20-29, 2009.

Corbineau, R., Reyerson, P. E., Alexandre, A., and Santos, G. M.: Towards producing pure phytolith concentrates from plants that are suitable for carbon isotopic analysis, Rev. Palaeobot. Palyno., 197, 179-185, 2013.

Cornelis, J.-T., Delvaux, B., Georg, R. B., Lucas, Y., Ranger, J., and Opfergelt, S.: Tracing the origin of dissolved silicon transferred from various soil-plant systems towards rivers: a review, Biogeosciences, 8, 89-112, doi:10.5194/bg-8-89-2011, 2011.

Currie, H. A. and Perry, C. C.: Silica in plants: biological, biochemical and chemical studies, Ann. Bot., 100, 1383-1389, 2007.

Elbaum, R., Weiner, S., Albert, R. M., and Elbaum, M.: Detection of burning of plant materials in the archaeological record by changes in the refractive indices of siliceous phytoliths, J. Archaeol. Sci., 30, 217-226, 2003.

Elbaum, R., Melamed-Bessudo, C., Tuross, N., Levy, A. A., and Weiner, S.: New methods to isolate organic materials from silicified phytoliths reveal fragmented glycoproteins but no DNA, Quatern. Int., 193, 11-19, 2009.

Gao, Y., Cheng, Z., Ling, W., and Huang, J.: Arbuscular mycorrhizal fungal hyphae contribute to the uptake of polycyclic aro- 
matic hydrocarbons by plant roots, Bioresource Technol., 101, 6895-6901, 2010.

Harrison, C. C.: Evidence for intramineral macromolecules containing protein from plant silicas, Phytochemistry, 41, 37-42, 1996.

Hatton, P.-J., Remusat, L., Zeller, B., and Derrien, D.: A multiscale approach to determine accurate elemental and isotopic ratios by nano-scale secondary ion mass spectrometry imaging, Rapid Commun. Mass Sp., 26, 1363-1371, 2012.

Herrmann, A. M., Clode, P. L., Fletcher, I. R., Nunan, N., Stockdale, E. A., O'Donnell, A. G., and Murphy, D. V.: A novel method for the study of the biophysical interface in soils using nano-scale secondary ion mass spectrometry, Rapid Commun. Mass Sp., 21, 29-34, 2007.

Hodson, M. J. and Sangster, A. G.: The interaction between silicon and aluminium in Sorghum bicolor (L.) Moench: growth analysis and X-ray microanalysis, Ann. Bot., 72, 389-400, 1993.

Huang, Z., Li, Y., Jiang, P., Chang, S. X., Song, Z., Liu, J., and Zhou, G.: Long-term intensive management increased carbon occluded in phytolith (PhytOC) in bamboo forest soils, Scientific Report, 4, 3602, doi:10.1038/srep03602, 2014.

Iler, R.: The Chemistry of Silica. Solubility, Polymerization, Colloid and Surface Properties, and Biochemistry, Chichester: John Wiley and Sons, 1979.

Instruments-for-research: SIMS: http://www.cameca.com/ instruments-for-research/sims.aspx, 2014.

Jones, R. L. and Beavers, A. H. Some mineralogical and chemical properties of plant opal. Soil Sci., 96, 375-379. 1963.

Kaufman, P. B., Dayanandan, P., Takeoka, Y., Bigelow, W. C., Jones, J. D., and Iler, R.: Silica in shoots of higher plants, in: Silicon and Siliceous structures in biological systems, edited by: Simpson, J. L. and Volcani, B. E., Springer Verlag, NY, 409-449, 1981.

Kealhofer, L. and Penny, D.: A combined pollen and phytolith record for fourteen thousand years of vegetation change in northeastern Thailand, Rev. Palaeobot. Palyno., 103, 83-93, 1998.

Kelly, E. F., Amundson, R. G., Marino, B. D., and Deniro, M. J.: Stable isotope ratios of carbon in phytoliths as a quantitative method of monitoring vegetation and climate change, Quaternary. Res., 35, 222-233, 1991.

Laue, M., Hause, G., Dietrich, D., and Wielage, B.: Ultrastructure and microanalysis of silica bodies in Dactylis glomerata L., Microchim. Acta, 156, 103-107, 2007.

Law, C. and Exley, C.: New insight into silica deposition in horsetail (Equisetum arvense), BMC Plant Biol., 11, 112, doi:10.1038/srep03602, 2011.

Li, B., Song, Z., Li, Z., Wang, H., Gui, R., and Song, R.: Phylogenetic variation of phytolith carbon sequestration in bamboos, Scientific Report, 4, 4710, doi:10.1038/srep04710, 2014.

Lins, U., Barros, C. F., da Cunha, M., and Miguens, F. C.: Structure, morphology, and composition of silicon biocomposites in the palm tree Syagrus coronata (Mart.) Becc., Protoplasma, 220, 89-96, 2002.

Madella, M., Alexandre, A., Ball, T., and Grp, I. W.: International code for phytolith nomenclature 1.0, Ann. Bot., 96, 253-260, 2005.

McInerney, F. A., Strömberg, C. A. E., and White, J. W. C.: The Neogene transition from $\mathrm{C} 3$ to $\mathrm{C} 4$ grasslands in North America: stable carbon isotope ratios of fossil phytoliths, Paleobiology, 37 , 23-49, 2011.
McMichael, C. H., Bush, M. B., Silman, M. R., Piperno, D. R., Raczka, M., Lobato, L. C., Zimmerman, M., Hagen, S., and Palace, M.: Historical fire and bamboo dynamics in western Amazonia, J. Biogeogr., 40, 299-309, doi:10.1111/jbi.12002, 2012.

Miller, L. A., Smith, S. Y., Sheldon, N. D., and Strömberg, C. A. E.: Eocene vegetation and ecosystem fluctuations inferred from a high-resolution phytolith record, Geol. Soc. Am. Bull., B30548.1, doi:10.1130/B30548.1, 2012.

Moore, K. L., Schröder, M., Wu, Z., Martin, B. G. H., Hawes, C. R., Mcgrath, S. P., Hawkesford, M. J., Ma, J. F., Zhao, F.-J., and Grovenor, C. R. M.: High-Resolution Secondary Ion Mass Spectrometry Reveals the Contrasting Subcellular Distribution of Arsenic and Silicon in Rice Roots, Plant Physiol., 156, 91324, 2011.

Motomura, H.: Silica deposition in relation to ageing of leaf tissues in Sasa veitchii (Carriere) Rehder (Poaceae: Bambusoideae), Ann. Bot., 93, 235-248, 2004.

Mueller, C. W., Kölbl, A., Hoeschen, C., Hillion, F., Heister, K., Herrmann, A. M., and Kögel- Knabner, I.: Submicron scale imaging of soil organic matter dynamics using NanoSIMS - from single particles to intact aggregates, Org. Geochem., 42, 14761488, 2012.

Mueller, C. W., Weber, P. K., Kilburn, M. R., Hoeschen, C., Kleber, M., and Pett-Ridge, J.: Advances in the Analysis of Biogeochemical Interfaces: NanoSIMS to Investigate Soil Microenvironments, Adv. Agron., 121, 1-46, doi:10.1016/B978-0-12407685-3.00001-3, 2013.

Müller, W. E. G., Wang, X., Sinha, B., Wiens, M., Schröder, H.-C., and Jochum, K. P.: NanoSIMS: insights into the organization of the proteinaceous scaffold within Hexactinellid sponge spicules, Chembiochem, 11, 1077-1082, 2010.

Neumann, D. and De Figueiredo, C.: A novel mechanism of silicon uptake, Protoplasma, 220, 59-67, 2002.

Oleschko, K., Parrot, J.-F., Ronquillo, G., Shoba, S., Stoops, G., and Marcelino, V.: Weathering: toward a fractal quantifying, Math. Geol., 36, 607-627, 2004.

Parr, J. F.: Effect of fire on phytolith coloration, Geoarchaeology, 21, 171-185, 2006.

Parr, J. F. and Sullivan, L. A.: Soil carbon sequestration in phytoliths, Soil Biol. Biochem., 37, 117-124, 2005.

Parr, J. F. and Sullivan, L. A.: Comparison of two methods for the isolation of phytolith occluded carbon from plant material, Plant Soil, 374, 45-53, 2014.

Parr, J., Sullivan, L., Chen, B., Ye, G., and Zheng, W.: Carbon biosequestration within the phytoliths of economic bamboo species, Glob. Change Biol., 16, 2661-2667, 2010.

Paungfoo-Lonhienne, C., Lonhienne, T. G. A., Rentsch, D., Robinson, N., Christie, M., Webb, R. I., Gamage, H. K., Carroll, B. J., Schenk, P. M., and Schmidt, S.: Plants can use protein as a nitrogen source without assistance from other organisms, P. Natl. Acad. Sci. USA, 105, 4524-4529, 2008.

Perry, C. C., Williams R. J. P., and S.C. Fry. Cell Wall Biosynthesis during Silicification of Grass Hairs, J. Plant Physiol., 126, 43748, 1987.

Piperno, D. R. and Becker, P.: Vegetational history of a site in the central Amazon Basin derived from phytolith and charcoal records from natural soils, Quaternary Res., 45, 202-209, 1996. 
Piperno, D. R. and Stothert, K. E.: Phytolith evidence for early Holocene Cucurbita domestication in southwest Ecuador, Science, 299, 1054-1057, 2003.

Piperno, D. R. Phytoliths. A Comprehensive Guide for Archaeologists and Paleoecologists. Lanham, New York, Toronto, Oxford: AltaMira Press (Rowman \& Littlefield), 2006.

Pironon, J., Meunier, J. D., Alexandre, A., Mathieu, R., Mansuy, L., Grosjean, A., and Jarde, E.: Individual characterization of phytoliths: experimental approach and consequences on paleoenvironment understanding, A. A. Balkema, Lisse, 2001.

Prychid, C. J., Rudall, P. J., and Gregory, M.: Systematics and biology of silica bodies in monocotyledons, Bot. Rev., 69, 377-440, 2003.

Sangster, A. G. and Parry, D. W.: Some factors in relation to bulliform cell silicification in the grass leaf, Ann. Bot., 33, 315-323, 1969.

Sangster A. G. and Parry D. W.: Ultrastructure of silica deposits in higher plants. In Silicon and siliceous structures in biological systems, ed. Simpson and Volcani, 383-407, New York, Heidelberg and Berlin, Springer-Verlag, 1981.

Santos, G. M., Alexandre, A., Coe, H. H. G., Reyerson, P. E., Southon, J. R., and De Carvalho, C. N.: The phytolith C-14 puzzle: a tale of background determinations and accuracy tests, Radiocarbon, 52, 113-128, 2010.

Santos, G. M., Alexandre, A., Southon, J. R., Treseder, K. K., Corbineau, R., and Reyerson, P. E.: Possible source of ancient carbon in phytolith concentrates from harvested grasses, Biogeosciences, 9, 1873-1884, doi:10.5194/bg-9-1873-2012, 2012.

Smith, F. A. and Anderson, K. B.: Characterization of organic compounds in phytoliths: improving the resolving power of phytolith delta $\mathrm{C}-13$ as a tool for paleoecological reconstruction of $\mathrm{C} 3$ and C4 grasses, in: Phytoliths - Applications in Earth Science and Human History, edited by: Meunier, J. D., and Colin, CRC Press, 317-327, 2001

Smith, F. A. and White, J. W. C.: Modern calibration of phytolith carbon isotope signatures for $\mathrm{C} 3 / \mathrm{C} 4$ paleograssland reconstruction, Palaeogeogr. Palaeocl., 207, 277-304, 2004.

Song, Z., Wang, H., Strong, P. J., Li, Z., and Jiang, P.: Plant impact on the coupled terrestrial biogeochemical cycles of silicon and carbon: implications for biogeochemical carbon sequestration, Earth-Sci. Rev., 115, 319-331, doi:10.1016/j.earscirev.2012.09.006, 2012.
Song, Z., Wang, H., Strong, P. J., and Guo, F.: Phytolith carbon sequestration in China's croplands, Eur. J. Agron., 53, 10-15, 2014.

Sowers, A. E. and Thurston, E. L.: Ultrastructural evidence for uptake of silicon-containing silicic acid analogs by Urtica pilulifera and incorporation into cell wall silica, Protoplasma, 101, 11-22, 1979.

Strömberg, C. A. E., Dunn, R. E., Madden, R. H., Kohn, M. J., and Carlini, A. A.: Decoupling the spread of grasslands from the evolution of grazer-type herbivores in South America, Nat. Commun., 4, 1478, doi:10.1038/ncomms2508, 2013.

Struyf, E. and D. J. Conley. Silica: An Essential Nutrient in Wetland Biogeochemistry, Front. Ecol. Environ., 7, 88-94. 2009.

Tegeder, M.: Transporters for amino acids in plant cells: some functions and many unknowns, Curr. Opin. Plant Biol., 15, 315-321, 2012.

Warren, C. R.: Post-uptake metabolism affects quantification of amino acid uptake, New Phytol., 193, 522-531, 2012.

Watling, K. M., Parr, J. F., Rintoul, L., Brown, C. L., and Sullivan, L. A.: Raman, infrared and XPS study of bamboo phytoliths after chemical digestion, Spectrochim. Acta A, 80, 106-111, 2011.

Webb, E. A. and Longstaffe, F. J.: Limitations on the climatic and ecological signals provided by the delta $\mathrm{C}-13$ values of phytoliths from a C4 North American prairie grass, Geochim. Cosmochim. Ac., 74, 3041-3050, 2010.

Whiteside, M. D., Treseder, K. K., and Atsatt, P. R.: The brighter side of soils: quantum dots track organic nitrogen through fungi and plants, Ecology, 90, 100-108, 2009.

Whiteside, M. D., Garcia, M. O., and Treseder, K. K.: Amino acid uptake in arbuscular mycorrhizal plants, PLoS ONE, 7, e47643, doi:10.1371/journal.pone.0047643, 2012.

Winterholler, B., Hoppe, P., Foley, S., and Andreae, M. O.: Sulfur isotope ratio measurements of individual sulfate particles by NanoSIMS, Int. J. Mass Spectrom., 272, 63-77, 2008.

Zhang, C., Wang, L., Zhang, W., and Zhang, F.: Do lignification and silicification of the cell wall precede silicon deposition in the silica cell of the rice (Oryza sativa L.) leaf epidermis?, Plant Soil, 372, 137-149, 2013.

Zuo, X., Lu, H., and Gu, Z.: Distribution of soil phytolith-occluded carbon in the Chinese Loess Plateau and its implications for silica-carbon cycles, Plant Soil, 374, 223-232, 2014. 